\title{
The Sooner the Better: The Arguments for the Use of Extended Welfare Assessment Grids in Animal Welfare
}

\section{Cases}

\section{Rachel Ann Dunn ${ }^{1}$}

Published online: 13 May 2020

(C) The Author(s) 2020

\begin{abstract}
Animals are protected under national animal welfare legislation, against intentional acts of cruelty and a failure to act, resulting in neglect and causing an animal to suffer. The Royal Society for the Prevention of Cruelty to Animals (RSPCA) bears the responsibility of investigating and prosecuting the majority of animal welfare offences in England and Wales. In recent years, how they operate has been criticised, and it has been debated whether they should be able to bring private prosecutions, and what their role should actually be. This criticism calls for a change in the way in which the RSPCA approach cases of animal welfare, to strengthen their continuing role in ensuring positive animal welfare is achieved and, where not, prosecuted. This paper outlines the need for a new approach and how it can be managed. Honess and Wolfensohn (Altern Lab Anim 38:205, 2010) have developed an Extended Welfare Assessment Grid (EWAG), a visualisation mapping tool of welfare impact, which has been useful for assessing the welfare of animals used in laboratories. This tool has proven so useful, veterinarians are now using it in veterinary hospitals to help assess whether an animal is likely to further deteriorate, due to disease and illness, and to show any short-term welfare impact on the animal (Williams in UFAW conference, Newcastle upon Tyne, 2018). This paper will explore the potential for the EWAG to be adapted to assess the welfare of animals when owners are not meeting the welfare needs of their companion animals. RSPCA can use it to support their assessments of the current welfare of an animal under a person's ownership and whether the animal's welfare will deteriorate should they remain under that ownership. The EWAG will be a useful tool for those working in animal welfare, such as the RSPCA, to help organisations to intervene earlier, work in partnership with an owner, and support their claims of a risk to animal welfare.
\end{abstract}

Keywords Animal welfare · Improvement notices · Extended Welfare Assessment Grid

Rachel Ann Dunn

rache12.dunn@northumbria.ac.uk

Extended author information available on the last page of the article 


\section{Introduction}

In 2018, the RSPCA received over 1 million phone calls to their cruelty line and rescued and collected more than 102,900 animals in England and Wales (RSPCA 2018). Whilst the Crown Prosecution Service (CPS) has the duty to investigate and prosecute criminal offences, it will be established in this article that the RSPCA bear most of the responsibility for animal welfare offences, by bringing private prosecutions. The RSPCA has been a source of prosecutions of animal welfare offences since the 1830's, and the number of prosecutions has steadily rose since then (Anderson 2012, 279). They are now facing some criticism, and it seems as though they may need to change how they approach inspection and prosecution of cases. Animal welfare assessment grids and tools are by no means a new concept. They have been used previously to measure welfare of farmed animals and animals used in experimental procedures. What does not seem to happen, or research has not shown, is the use of similar tools for assessing the welfare of animals for offences under the Animal Welfare Act 2006. Further, many of the tools currently used are not visual or used with owners. This paper advocates for the development and use of an Extended Welfare Assessment Grid (EWAG), to be used in animal welfare cases in England and Wales, in cases involving domesticated companion animals. There is no reason as to why this tool could not be used in other jurisdictions, but the potential international reach is not the focus of this article. Due to the extent which the RSPCA investigate and prosecute animal welfare offences, this article will focus mainly on the application to this organisation, but similarly, there is nothing to prevent Local Authorities or police forces adopting it also.

It should be emphasised at the outset that the aim of this paper is not a theoretical one, such as ethical and philosophical questions around our non-human companions, and does not engage in discussion of the use of animals or whether they should be kept as pets or have property status. This paper is advocating for a different way in which we can assess animal welfare under the Animal Welfare Act 2006, and is thus very practical in nature. It outlines how it is envisaged that the grid will work in practice, and how it can contribute to working with owners to improve welfare during an improvement notice period and, potentially, as evidence in any subsequent prosecutions. Thus, this paper is demonstrating the need for this tool, which will be followed by an empirical research project to develop the tool with key stakeholders in the near future.

This article will begin by providing an overview of the relevant animal welfare law, specifically under the Animal Welfare Act 2006. Next, it will highlight the issues which are faced by the RSPCA at this time, mainly the claims they should not be bringing private prosecutions and the actions that they take should be limited. Throughout these sections, the importance of the RSPCA and the work they do is emphasised. A discussion of different current welfare tools is presented before presenting the original EWAG and then the modified version for animal welfare cases. The case will also be made of how this tool can increase the participation of owners to promote and improve their animal's welfare, as well its 
use as evidence in any subsequent criminal proceedings, is presented. This article concludes that further research is needed in order to effectively develop the EWAG for consistent use across the jurisdiction and fully understand the potential it has for those who may be using it.

\section{Overview of Relevant Animal Welfare Law}

Animal offences in England and Wales are governed by the Animal Welfare Act 2006 (AWA), which replaced the Protection of Animals Act 1911. It retained the similar offence of unnecessary suffering under s.4 AWA, which is committed if a person acts, or fails to act, in a way which causes an animal to suffer unnecessarily. ${ }^{1}$ AWA made significant changes to previous animal welfare legislation, namely the introduction of the promotion of animal welfare under s.9. This means that owners have to ensure the animal in their control has a suitable environment, diet, is able to exhibit normal behaviour patterns, be housed with, or apart from other animals and be protected from pain, suffering, injury and disease. ${ }^{2}$ The consequence of this section meant that an inspector could intervene before an animal actually suffers, whereas prior to the 2006 Act, suffering had to take place before any action could be taken. When the Animal Welfare Bill was introduced, the then RSPCA Director General stated, 'Every single day RSPCA inspectors have to watch in frustration and sadness as the neglect of numerous animals at risk turns into suffering. The Animal Welfare Bill would mean we could act before that suffering actually happens' (BBC 2014).

Under s.18 AWA an inspector or constable can take an animal into their possession if a veterinary surgeon certifies that 'it is suffering, or, that it is likely to suffer if its circumstances do not change. ${ }^{3}$ Further, they can take an animal in their possession without a certificate if it appears to them that the animal is suffering, or will likely suffer if circumstances do not change, and the action needed is not reasonably practicable to wait for a veterinary surgeon. ${ }^{4}$ It is important to note that inspectors' do not include RSPCA Inspectors. If an RSPCA Inspector believes that there is suffering to justify action under s.18, they must inform a police constable or Local Authority inspector to carry out this action.

If there is enough evidence to bring a prosecution, they can apply to deprive an owner of that animal ${ }^{5}$ and even disqualify them from owning animals of the same kind or generally for a specified amount of time. ${ }^{6}$ If a person gains possession of an

\footnotetext{
1 Animal Welfare Act, s.4(1).

2 Animal Welfare Act, ss.9(2)(a)-(e).

3 Animal Welfare Act, s.18(5)(a)-(b).

4 Animal Welfare Act, 18(6)(a)-(b).

5 Animal Welfare Act, s.33.

6 Animal Welfare Act, s.34.
} 
animal contrary to an order during this disqualification period, this is an offence and the animal can be seized. ${ }^{7}$

\section{Improvement Notices}

Improvement notices can be served on a person who an inspector believes is failing to comply with the welfare needs under s.9(1). ${ }^{8}$ This will specify why the inspector considers a person to be failing to comply, the steps needed to be taken in order to comply with the provision, a specified period for taking these steps and the effects of non-compliance with the improvement notice. ${ }^{9}$ During this time period, no proceedings can be instituted for the non-compliance which initiated the notice or continued non-compliance. ${ }^{10}$ Further, if the notice is complied with during this time, no proceedings can be taken after the notice period. ${ }^{11}$ This period can be extended by an inspector. $^{12}$

During the Parliamentary debates of the Animal Welfare Bill 2005, there was much discussion around whether to include a statutory improvement notice. Some ministers believed it would restrict relevant authorities from taking immediate action when an animal is suffering, feeling the need to issue an improvement notice first. ${ }^{13}$ This was not accepted by the Committee, who stated:

...if the Bill remains silent on the issue we consider that there is a risk that enforcement agencies will believe that they have no option but to prosecute in order to ensure an animal's welfare. We consider that improvement notices would assist in ensuring that proceedings are commenced only in appropriate cases. They would not only save court time but could also encourage owners to improve standards of animal welfare. ${ }^{14}$

There is a clear advantage to issuing improvement notices and the Committee wanted to make sure that this option was available, so that the standard of animal welfare can be improved, rather than bring prosecutions which could be avoided by working with an owner.

There have not been any definite figures released of how many statutory improvement notices were issued, but it has been indicated in 2010 that there were 148 notices issued over 2 years by Local Authorities in Wales. Local Authorities in

\footnotetext{
7 Animal Welfare Act, s.35.

8 Animal Welfare Act, s. 10.

9 Animal Welfare Act, s.10(1)(a)-(e).

10 Animal Welfare Act, s.10(2).

11 Animal Welfare Act, s.10(3).

12 Animal Welfare Act, s.10(4).

13 Select Committee on Environment, Food and Rural Affairs, First Report: The Draft Animal Welfare Bill, (HL 2004-05 52-I), Col 240.

14 Select Committee on Environment, Food and Rural Affairs, First Report: The Draft Animal Welfare Bill, (HL 2004-05 52-I) Col 242.
} 
England reported similar numbers of the use of these notices. ${ }^{15}$ This is less, however, than RSPCA improvement notices, which are discussed below. More recent figures of Local Authorities' use of statutory improvement notices are not available, and it is not clear whether, since 2010, their use has gone up, or if predominantly the RSPCA are continuing to ensure that an owner is improving their pet's welfare, rather than the state.

S.10 of AWA stipulates what a statutory improvement notice must contain. Specifically:

(1)If an inspector is of the opinion that a person is failing to comply with section 9(1), he may serve on the person a notice which-

(a)states that he is of that opinion,

(b)specifies the respects in which he considers the person is failing to comply with that provision,

(c)specifies the steps he considers need to be taken in order to comply with the provision,

(d)specifies a period for the taking of those steps, and

(e) explains the effect of subsections (2) and (3).

This notice should outline in detail what an owner needs to do to improve their pet's welfare and when they need to have made the improvement(s) by. There is no set template for a statutory improvement notice, but a standard template was provided by DEFRA. Local Authorities, however, are able to use their own version or template if they wish (Department Environment, Food and Rural Affairs). Vets do not need to be consulted when a statutory improvement notice is being issued (The National Archives 2009). There is no evidence found at this time of the effectiveness of the different templates and whether more consistency is needed between different Local Authorities, and this may require further research.

\section{RSPCA Improvement Notices}

Prior to AWA, there was no statutory duty to follow an improvement notice. When debating the Animal Welfare Bill, it was noted that the RSPCA notices, whilst helpful, may have been 'perceived as a threatening or intimidating', and that, 'even if they are well intentioned and justified, there is no requirement to comply. ${ }^{16}$ Interestingly, during this debate, it was highlighted how the RSPCA did not wish to gain a statutory power to issue notices and it would be sensible that only Government bodies had such powers. Further, there were concerns that the Minister during these

\footnotetext{
15 Memorandum to Environment Food and Rural Affiars Committee: Post-Legislative Assessment of the Animal Welfare Act 2006, 2010, 13.

16 Animal Welfare Bill Deb 2006, Col 314.
} 
debates was 'relying too much on the RSPCA to enforce legislation, when Government bodies predominately should prosecute under criminal law.' 17

The RSPCA still issue their own improvement notices and in 2018 more than 66,169 notices were issued (RSPCA (a) 2018, 29). There are claims that these improvement notices work, as the number of prosecutions has gone down with more notices issued (Snowdon 2017). ${ }^{18}$ These claims, however, are not arguable for the present time, as convictions have gone up and less improvement notices were issued in 2018 than previous years. There is a correlation seen, that the more improvement notices granted the less convictions there are, but this data cannot fully support the argument that the improvement notices work, in that owners improve welfare of their pets and no further action is taken. This was highlighted in a debate of the Animal Welfare Bill, specifically that of the 257 RSPCA improvement notices issued in 2005, 240 led to improvement of the welfare on the animal and only 17 instances where the notices were not acted upon. ${ }^{19}$ This data is not published by the RSPCA in their current prosecution reports and not available. There is also not a readily available template of an improvement notice, and the RSPCA does not provide much information or guidance as to what one they would contain.

\section{The Issues with Animal Welfare Law and Enforcement}

There have been several issues raised in terms of AWA, namely the actions of the RSPCA when using it. When the Animal Welfare Bill was being debated, the vital role of the RSPCA was highlighted. In the third report of the Animal Welfare Bill, they considered the questions of NGOs, particularly the RSPCA, to be able to bring private prosecutions for animal welfare offences. The Committee stated that:

We consider these concerns misplaced. Animal welfare legislation has, as a matter of common law, always been private enforcers' law. The role of the RSPCA in particular in enforcing animal welfare law is fundamental, and it would be entirely inconsistent with the aims of this Bill if we were to take away their power to bring prosecutions. ${ }^{20}$

There have been many sentiments such as this, and the RSPCA has long been seen as a staple in our society to enforce animal welfare legislation, without which many cases may not arise and/or not be known about.

Since the introduction of AWA, the RSPCA have come under fire again for their investigatory and prosecuting actions. For example, there were instances of the RSPCA taking an animal into their possession and, whilst they had explained the

\footnotetext{
17 Animal Welfare Bill Deb 2006, Col 316.

18 For example, in 2016 84,725 notices were issued, up from 81,475 in 2015. In this time, prosecutions by the RSPCA dropped from 1781 to 1477.

19 Animal Welfare Bill Deb 2006, Col 320.

20 Environment, Food and Rural Affairs Committee, Animal Welfare Bill: Third Report of Session 200606 (HC 683 2004-05) EV 7, Paragraph 62.
} 
situation to a vet to get a s.18 certificate signed, the vet had not seen the animal to verify the suffering themselves. This has also meant that they have potentially been taking animals away from owners where there is poor evidence of an offence and the animal should not have been removed (Hope 2016). Some have claimed that they are pushing an animal rights agenda, rather than focusing on protecting animal welfare. For example, Countryside Alliance, a pro-hunting organisation, have argued that the RSPCA need to focus on cases of individual welfare issues, rather than focusing on an animal rights agenda (Countryside Alliance 2017). This issue has been debated in the House of Commons, led by Simon Hart, who questioned why the RSPCA was spending such a substantial amount of money every year when other charities, such as the National Society for the Prevention of Cruelty to Children (NSPCC), rely on the CPS and police to deal with issues. ${ }^{21}$ This seems an unfair comparison, when one considers the anthropocentric importance attached to child abuse and neglect cases compared to that of animal abuse and neglect cases. Additionally, social services deal specifically with child care cases, with resources dedicated to ensuring safety of children and the ability to bring cases to both the criminal and family courts if the welfare of the child is not being met. Animals do not have this level of protection, and the RSPCA are the main organisation which investigates reports of animal cruelty, and funds prosecutions and the care of animals when taken from their owner(s).

Hart further questioned the RSPCA's and expertise to bring these prosecutions, stating:

There are numerous examples of the RSPCA failing to prosecute when there is evidence with which to do so, and vice versa, and that gets to the nub of the debate. The charity sometimes pursues tantalising cases, at not only considerable public and private cost but to the cost of some innocent victims, some of whom plead guilty simply because of the fear of the huge cost risks of doing otherwise and finding themselves on the receiving end of this massive financial machine. ${ }^{22}$

These are strong claims and they do need to be considered, but the issue is that the RSPCA brings the majority of prosecutions for animal welfare offences, with claims that they are responsible for over $90 \%$ of prosecutions involving animal welfare issues. ${ }^{23}$ Whilst the RSPCA had indicated they accept that the CPS could do the majority of the prosecution work, they highlight that the CPS do not have their wealth of experience and knowledge, ${ }^{24}$ which arguably is needed for successful prosecutions. Alison Seabeck, during the debate, argued that if the RSPCA's powers 'are revoked in any way, hundreds of cases of animal cruelty in the UK will go

\footnotetext{
21 HC Deb 29th January 2013, Vol 557, Col 181WH.

22 HC Deb 29th January 2013, Vol 557, Col 186WH.

23 Environment, Food and Rural Affairs Committee, Animal Welfare in England: Domestic Pets: Third Report of Session 2016-17 (HC 117 2016-17), 27.

24 Environment, Food and Rural Affairs Committee, Animal Welfare in England: Domestic Pets: Third Report of Session 2016-17 (HC 117 2016-17), 27.
} 
unchallenged each year. Its role is vital. ${ }^{25}$ Caroline Lucas also pointed out that the RSPCA has a 98\% success rate for their prosecutions and the CPS only has $50 \% .^{26}$ Further, even though the RSCPA can bring their own prosecutions, if the defendant or their solicitor wishes the CPS to take over, they can request this to happen.

In 2014, the Wooler Review was published, outlining the current issues with RSPCA prosecutions and recommendations to improve their standing in society and operate more smoothly. Wooler identified that the combination of criticism and a relentless media campaign has had an adverse, and in many resects disproportionate, impact on the Society's standing' (Wooler 2014, 10). This is unfortunate, due to the fact that the RSPCA bring the majority of prosecutions. Just over $60 \%$ of Local Authorities in England had appointed inspectors under AWA when this report was written, with little focus on resources for companion animals, and nearly $40 \%$ of them said they would always refer such matters to the RSPCA (Wooler 2014, 13). Further, issues were found within the evidence provided by vets, seemingly that they adopted their own approach as to what constitutes as suffering, which could most often be personal opinion. It was recommended that the RSPCA work with the 'Royal College of Veterinary Surgeons and other practitioners to develop a common standard or guidance on the approach to the assessment of suffering' (Wooler 2014, 26). The RSPCA welcomed the recommendations, and acknowledged the need to identify how they can carry out their investigatory and prosecution role in a way which is more efficient, effective, and consistent with expectations of accountability and transparency (RSPCA 2014). Some of the recommendations put forward by Wooler have already been implemented. To increase this accountability and transparency, as well as helping to achieve consistency across branches, the EWAG will be a useful tool.

Some have argued that, whilst AWA was a necessary statute for the protection of animals, it is not reaching its full potential. For example, the British Veterinary Association submitted evidence to the Environment, Food and Rural Affairs Committee in 2016 on domestic animal welfare, stated that they were concerned that people did not know of their responsibilities under s.9 (British Veterinary Association and British Small Animal Veterinary Association 2016, para 14). They further acknowledged that $\mathrm{s} .9$ can be difficult to enforce, and that 'there is no clear process for the practicalities of enforcing the five animal welfare needs and it seems that usually active suffering still has to occur before action is taken' (British Veterinary Association and British Small Animal Veterinary Association 2016, para 5). This is not what s.9 was designed for, as its aim is to remove an animal before suffering has taken place because their needs have not been met. This issue is something the EWAG can aid.

\footnotetext{
${ }^{25}$ HC Deb 29th January 2013, Vol 557, Col 190WH.

${ }^{26}$ HC Deb 29th January 2013, Vol 557, Col 201WH.
} 


\section{Welfare Assessment Grids}

Before the EWAG is presented and discussed, it is important to highlight that this is not the first welfare assessment grid to be used, and there have been a variety of grids developed and used in animal welfare cases. This section will discuss some of the established ways in which animal welfare is assessed and their uses.

Some grids which have been developed look more like tables, rather than a more pictorial grid. An Animal Welfare Impact Assessment Tool was developed for use and application in Bovine Tuberculosis (bTB) and badger control (McCulloch and Reiss 2017). This tool, whilst not as visual as the EWAG, was welcomed by those working in the realm of bTB, as it helped to bring some objectivity to the issue and the decision made on culling (McCulloch and Reiss 2017, 504). The use of welfare assessment tables has also been developed when measuring the welfare of farm animals. Botreau et al. (2009) use a table with the categories 'Good Feeding', 'Good Housing', 'Good Health' and 'Appropriate Behaviour', with 12 welfare criteria to support the evaluation, and a 0-100 value scale. The authors argue that this tool can be used for multiple purposes, including giving farmers a broad picture of the welfare status of their animals' and 'to facilitate informed decision by stakeholders, including consumers' (Botreau et al. 2009, 369-370). Others working in welfare assessment of farmed animals have develop mobile device apps to support farmers when applying the Animal Welfare Indicators to their livestock. Heuston et al. $(2017,7)$ state that the 'real-time output [of the app] can facilitate dialogue with farmers, suggesting actions to improve the welfare of animals' and that it 'increases the efficiency and standardization of on-farm welfare assessment.' Thus, it is not only the welfare assessment tool, but also the user function and accessibility of the tool to the owner of an animal, which is important for its success.

Whilst many of the welfare assessment tools discussed in this section are for the use of welfare of farmed animals, a version of the EWAG has been developed for animals in zoos. The physical display is different to that of the EWAG presented below, and is not seemingly as sophisticated, even though developed by one of the same researchers. What was found, however, is that using the grid and plotting cumulative scores over time can be 'helpful for identifying events that may be perceived as detrimental to welfare and avoiding these in the future' (Justice et al. 2017, 150). This paper highlights, importantly, that using welfare assessment grids does not only indicate where improvement is needed to animal welfare, but also demonstrates good practice and perceived positive welfare. This observation becomes important during the next section of this article.

The importance of welfare assessment for animals is not only to help alleviate the suffering that they could be feeling, but also to communicate with owners the impact of this suffering on the animal's life. For example, Fordyce (2017) developed a welfare scoring system for Intensive Care Unit patients, finding that it assisted discussions with owner(s) and other clinicians the actual and projected welfare of the animal about treatment options. This is consistent with work by Williams (2018).

They do not come without issues, though, and welfare assessment tools can be used with varying consistency, between different users, as shown in previous research 
on dairy farms by Stull et al. (2005). Experts can differ on opinions of animal welfare and behaviour, regardless of the similarity of their training and expertise, and can be influenced by bias (Norwood and Lusk 2011, 108). Whilst each animal welfare matter should be assessed individually and based on that specific animal and the facts of the case, it may be inappropriate to conclude welfare on single assessments (Kirchner et al. 2014). Difficulties may arise by applying an assessment of an individual animal to a whole group of the same species, and the differences between individuals needs to be considered (Justice et al. 2017, 151). In the context of domestic animal welfare cases, just because one spaniel is suffering under a particular ownership, for example, does not mean that the owner's other spaniel also is (Hewson 2003). Moreover, the welfare of an animal will differ between species and it will be important to consider each when designing this tool. This is why it is important to develop a key to the EWAG, or welfare indicator, to standardise use across the country and to maintain the reliability of the tool when used as evidence in criminal proceedings.

\section{Increasing Positive Participation in Improving Welfare}

The purpose of the tool demonstrated and advocated for in this article does not have the sole purpose of providing evidence in order to remove a pet and bring criminal proceedings. Before an animal is removed, unless they are suffering to an extent that immediate removal is necessary, the objective should be to work with an owner to understand their pet's welfare needs, why they are not being met, and how they can be improved. This has the benefit of a potential decrease in the number of animals who are rescued due to increased welfare and better understanding. It is appreciated that the RSPCA and governmental or Local Authority inspectors can issue improvement notices, but they are written notices, and it is unclear what advice is given with them and how useful they are in more recent times. Whilst it was outlined above that improvement notices have appeared to have worked in the past, this was prior to the increasing issues and hostility the RSPCA have faced in present times. The use of the EWAG may strengthen their relationship with owners and provide information which is easier to understand and promotes collaboration.

Hawkins et al. (2011, 2), have identified general principles for an effective welfare assessment scheme:

1. 'A team approach

2. Appropriate welfare indicators

3. A sound understanding of good welfare and the 'normal' animal

4. Full recognition of all potential adverse effects from all sources

5. Consistency for all species

6. Consistency between observers

7. Appropriate recording systems'.

The EWAG does all of the above, and using it with owners of domesticated animals, rather than against them, may ensure lasting improved welfare standards and 
less cases needing to be prosecuted. The main principles to be discussed here are a team approach and appropriate recording systems.

Hawkins et al. (2011) describe a 'team approach' as including a range of people with relevant roles and expertise, and it is argued that this animal assessment scheme should also include the owner(s) or the animal as part of that team. Due to the issues with RSPCA cases outlined above, and the potential distrust currently of RSPCA Inspectors, working with the owner as a partner in increasing welfare could be a way to break the barrier and gain trust. This 'team approach' is the best way to ensure consistency and effectiveness in managing adverse effects,' (Hawkins 2002, 383 ), and whilst the principles originate from laboratory studies, there is no reason as to why this cannot extend to domesticated animals.

This will be helped through the principle of an 'appropriate recording system'. This appropriateness must apply to those observing an animal's welfare, as well as to the owner, and so must be easy to understand and suitable for a variety of users. One of the ways in which to do this is by usual a visual tool, supported by other means of communication, which can be used to relay complex information. Not only will a visual tool help an owner to understand what the issue is with their pet's welfare, but it can also help them track improvement and stimulate positive behaviour. This has been proven in a variety of other areas, such as visual management. In organisations, visual management has been used to enhance the information flow in organisations (Eaidgah et al. 2016). Bilalis et al. (2002, 3578), when conducting research into effective information transfer in a work setting, argue that for information to be effectively communicated it must be 'visible, clear and simple in its presentation.' A literature review of visual management in the work place found that using visual methods to communicate information can improve processes in a company and stimulate continuous improvement (Jaca et al. 2014). In the field of health, studies have found that visual aids can help to promote healthy behaviour in patients and can be helpful for people who have difficulties understanding information about health risks (Garcia-Retamero and Cokely 2013). This is consistent with research discussed above, concerning how a welfare assessment grid in zoos can outline perceived positive welfare and good practice.

Overall, it seems as though visual aids can improve understanding of those who need to comprehend complex information and can promote better and sustainable performance, moving toward an outcome-based approach. Previous research shows this to be effective in other fields, and there is no reason as to why this should not be the case for animal welfare cases, which at the moment does not seem to utilise visual tools.

\section{Extended Welfare Assessment Grid (EWAG)}

The EWAG was originally developed by researchers using animals in clinical trials, to provide for, 'the incorporation of changes in the state of an animal over time, allowing for predictive, retrospective, scheduled, or event monitoring' (Honess and Wolfensohn 2010, 205). Honess and Wolfensohn's EWAG is displayed in Fig. 1. 


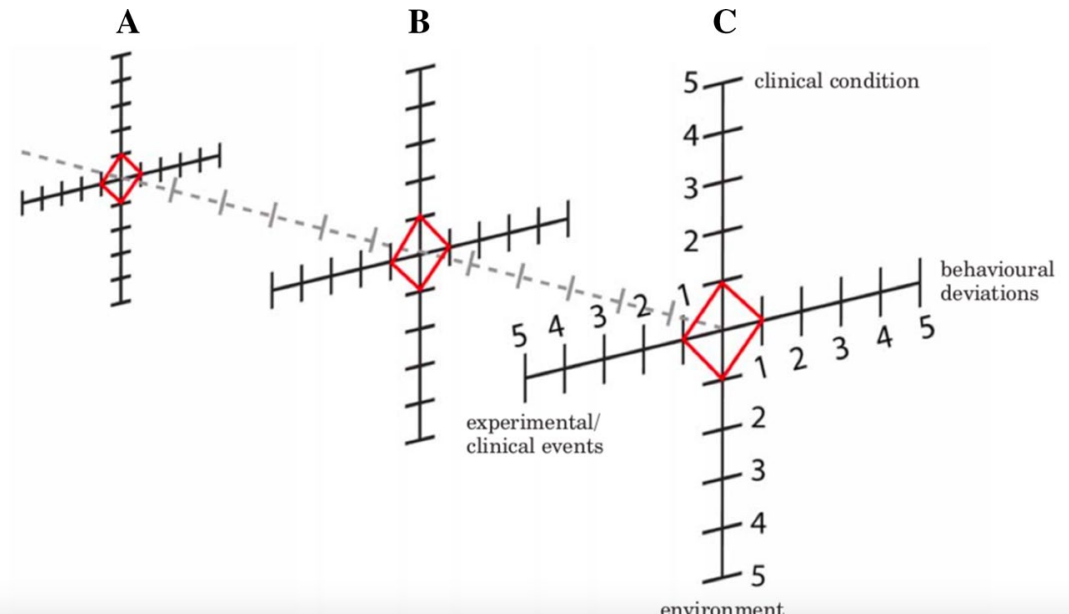

Fig. 1 The Extended Welfare Assessment Grid (Honess and Wolfensohn 2010, 207)

They have derived the four categories seen on the axis from the Five Freedoms, which are those adopted into s.9(1) AWA. We can see that the grid has been extended and provides for measurement at different stages during an experiment, to account for that change over time. With the aid of computer software, this will be visually mapped for each of the different categories, creating a time projection, with 1 being mild and 10 being severe on the scale. Using a numerical system, with a scoring system, can contribute to assessing cumulative suffering and be the basis for complex assessments of welfare (Hawkins et al. 2011).

Outlined above, some animal welfare assessment tools only measure welfare at a single point of time, rather than over an extended period. This tool has been developed to monitor lifetime experience, and 'has particular value in producing a simple, objective, visual illustration of cumulative suffering' (Wolfensohn et al. 2015, 148). The limitations of this grid will be discussed during a later section of this article, putting it into context of the issues which may be faced by the RSPCA or other governmental inspectors.

\section{How Can EWAG Be Used in Animal Welfare Cases?}

To reiterate, in 2018 more than 66,169 notices were issued and 1182 cases were reported to the RSPCA Prosecutions Department (RSPCA (a) 2018, 29).It was highlighted in the debates around the Animal Welfare Bill that many people who are charged with s.9 offences are ignorant of welfare offences and do not know how to look after their animals properly. Thus, a rush to a prosecution in these cases may not be appropriate and an improvement notice will help them to improve the welfare of an animal. ${ }^{27}$ As outlined above, an improvement notice consists of what welfare

27 Animal Welfare Bill Deb 26 January 2006 Col 317. 
issues there are with an animal, the steps needed to improve the situation and a time frame for doing so. Honess and Wolfensohn have demonstrated the use of the EWAG for short and mid-term trials, demonstrating its applicability at different time intervals (Wolfensohn et al. 2015, 148). Thus, an improvement notice period, which is usually over one month, will be enough time to measure changes on the EWAG. Having something visual may be more helpful than words on paper, to highlight the urgency of a welfare situation and to promote change. It is not clear from the literature why a tool of this kind has not yet been extended to cases in domestic animal welfare, particularly when already used in other contexts, such as zoos (Justice et al. 2017), and there is a need to avoid speculation as to why. What is emphasised is how useful this tool could be to those working toward animal protection and welfare, as an alternative to current practice and to increase the justification for seizing animals and prosecuting animal welfare offences.

The EWAG will need to be adapted for uses in animal welfare protection, rather than in clinical trials. This adaption would be both what is measured on the EWAG and how it is calculated, as those using this tool would not be scientists. Further, some categories on Honess and Wolfensohn's EWAG relate very specifically to animals used in experiments, such as the experimental/clinical events the animals are subjected to. Thus, the EWAG for this research has been modified to represent the s.9 AWA different categories which promote animal welfare. My EWAG looks like in Fig. 2.

It can be seen that this EWAG includes all five of the welfare promotions, but has included s.9(2)(d), the need to be housed with or apart from other animals, within s9(2)(a) and the need for a suitable environment. With only four axes, it seemed best to amalgamate these promotions, as they are similar in nature. How this is used in practice will need to be explored further, and the plan for this is discussed further below, but this section will outline how it is envisaged it to work. It is also important to note that a vet has not contributed to this paper, so the scenarios here, whilst based on real cases, are anecdotal and not scientifically dependable.

The following use of the EWAG will be illustrated with a scenario of a dog who has been reported to the RSPCA and an RSPCA Inspector has attended a property to assess their welfare. The RSPCA Inspector notes that the dog is housed in a suitable environment, they have been given veterinary care when needed, but is not fed a suitable diet and, as a result, is overweight. This restricts the dog from being able to walk and play with other dogs, limiting its ability to exhibit normal behaviour patterns. ${ }^{28}$ When assessing this suffering one may think that the points on the scale will be as follows:

- Suitable diet $=8$. The animal is not being fed food suitable for its species and is now so large that it is causing it health issues. If this does not change then it will cause further health difficulties and complications.

\footnotetext{
${ }^{28}$ This scenario is based on a real case, which did not reach court, but can be read about here: http:// news.bbc.co.uk/1/hi/england/cambridgeshire/6256349.stm.
} 


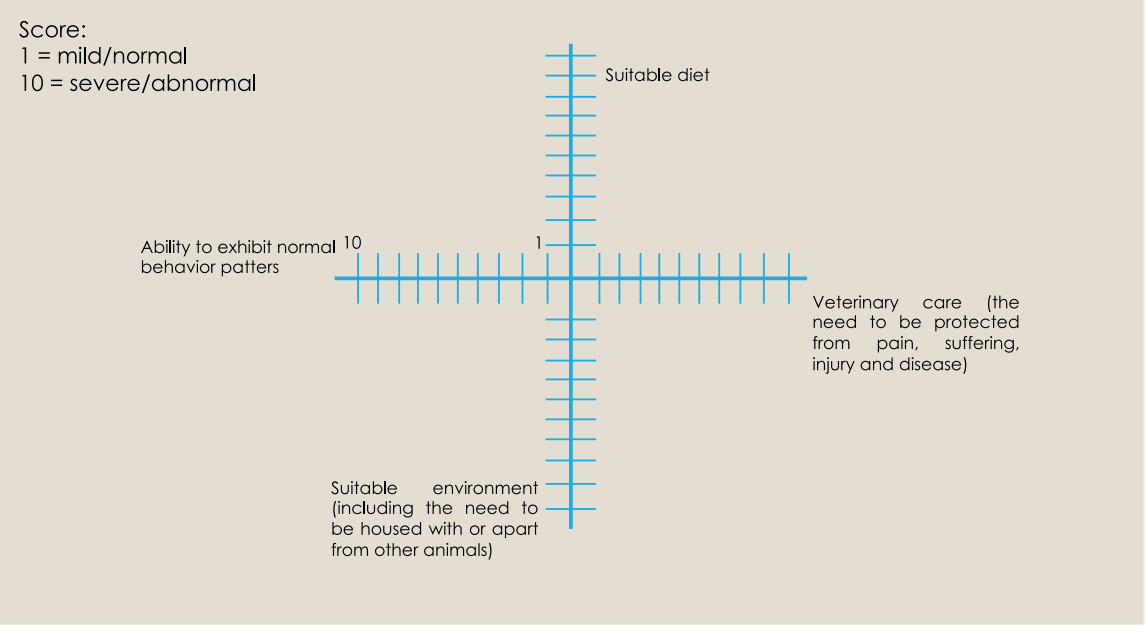

Fig. 2 The EWAG for improving the welfare of animals under the Animal Welfare Act 2006

- Ability to exhibit normal behaviour patterns $=7$. Due to the animal being overweight, they cannot run and play with other dogs. This means that the dog is not getting the exercise needed for their health and potentially not socialising adequately with other dogs.

- Veterinary care $=2$. At the moment, there is no evidence that the dog is suffering from pain and injury caused by being overweight, apart from pressure on their joints and other minor health disadvantages.

- Suitable environment $=1$. There are no welfare concerns about the dog's environment and it is completely suitable for the species.

This assessment will be concluded by working with a key to the EWAG. For example, the RSPCA may note that the dog is $8 \mathrm{~kg}$ heavier than they should be for their breed, so they are an 8 on the scale according to the key which will be developed by experts. An inspector may feel as though this can improve with the owner's intervention, but needs to display this visually. Thus, at the moment, the dog's welfare looks like Fig. 3.

The RSPCA Inspector works with the owner to develop this grid, explaining why it has been mapped in this way. They provide further information of how to help the dog lose weight, explaining what a suitable diet is for their species and how often exercise should be encouraged. The RSPCA Inspector returns to assess the $\mathrm{dog}$, either during the notice period or afterwards. If the owner does nothing about the situation, it could progress to look like Fig. 4. 


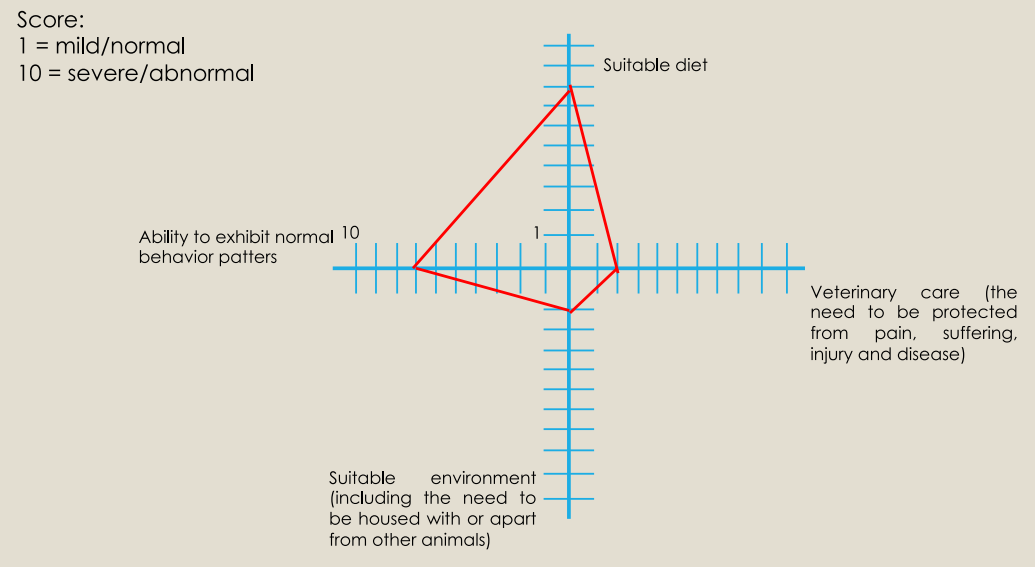

Fig. 3 Welfare assessment grid for scenario

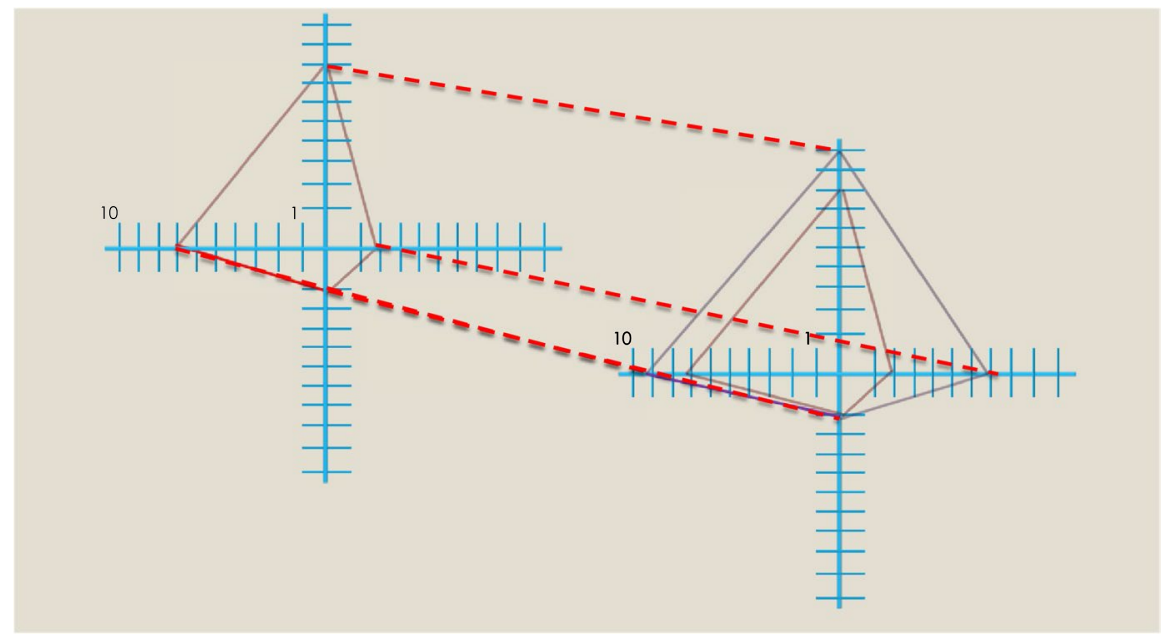

Fig. 4 Extended welfare assessment grid for scenario (decrease of welfare)

We can see from the EWAG that the welfare of the dog has gotten worse. Not only has suitable diet and ability to exhibit normal behaviour patterns decreased in terms of welfare, but so has veterinary care. This is due to the dog no longer being able to walk and therefore cannot urinate outside; they have been sitting in their own urine and this has caused contact dermatitis. The health issues associated with the obesity means that the dog will be on medication for the rest of their life to avoid any further suffering. 


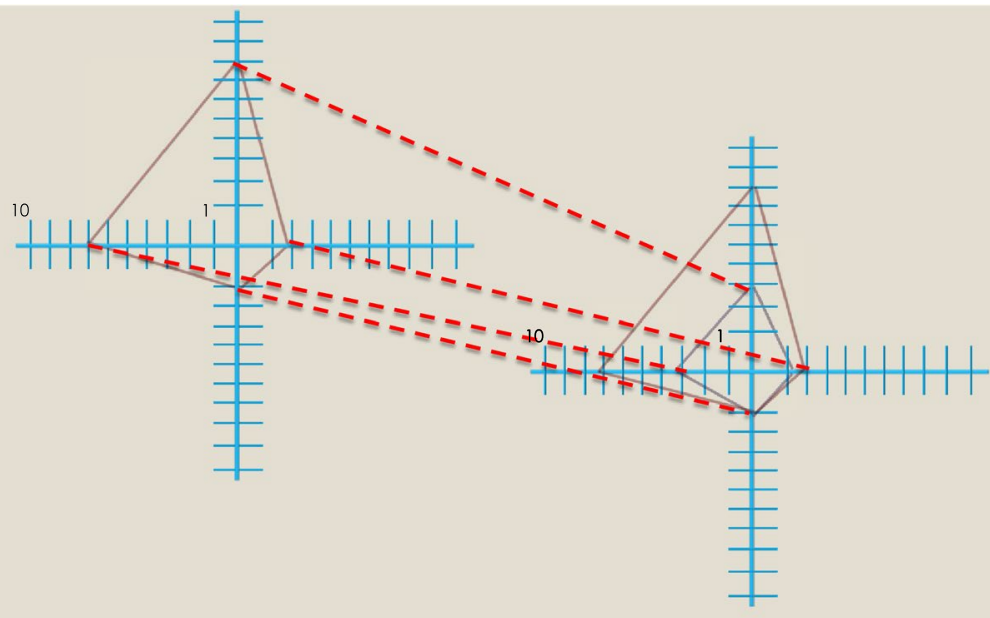

Fig. 5 Extended welfare assessment grid for scenario (increase of welfare)

Alternatively, if the owner works with the improvement notice to improve the diet of the dog and their overall welfare, it could like Fig. 5.

In the timeframe of the improvement notice, we see that the owner has changed the diet of their dog and that the dog has started to lose weight. They may not yet be in perfect health, but the change in diet means that they are now able to exercise more easily and exhibit normal behaviour patterns. This has also decreased their need for veterinary care.

This rudimentary example of how the EWAG can be used in animal welfare cases may not be representative of the majority of cases the RSPCA and other inspectors face, but explains how the tool can visually represent the welfare of an animal. Further, having a key with accompanies the EWAG can help to increase consistency of use and reliability across different areas of England and Wales, with the design of a variety of experts and stakeholders.

\section{Improvement Notices}

As demonstrated above, the EWAG can be used during the improvement notice period. The person issuing the notice can draft an EWAG displaying the welfare and suffering of the animal at the moment. They can then draft EWAG to show the owner how the welfare will decrease, should they make no changes, or increase, should they follow the steps in the improvement notice. By showing them this, it may help them to realise the issues with their pet and how drastically it can worsen should they fail to act, or continue to act as they are.

Further, the person may wish, when monitoring improvement, to re-draft the notice, to show the owner how well, or not well, they are doing with improving the welfare of their pet. This may help to encourage them to continue with their 
efforts, consistent with the previously cited studies that show visual representations of information can improve performance. Honess and Wolfensohn highlight that the EWAG can be 'used to support a course of action to resolve a problem, and show the accumulated benefits in terms of the resultant reduction in suffering. Importantly, it could also highlight where poor practice and welfare management need attention' $(2010,211)$. Whilst this evaluation of the EWAG is specifically aimed at experiments involving animals, the conclusions can be used to support animal welfare and protection cases also. Ultimately, the goal in anything involving animals is to promote welfare and reduce suffering, and a visual tool may better aid this goal than a written notice.

\section{Evidential Uses}

As stated above, no prosecutions can be brought during an improvement notice period, but they can be afterwards if there is no improvement in welfare. It may be that after the expiry of the improvement notice, the welfare of the animal has not changed or decreased so drastically that the animal needs to be removed from their owner. If a s.9 AWA offence is prosecuted, the body bringing the prosecution, usually the RSPCA, will need evidence of the suffering. They usually have this through veterinary expert evidence statements and other evidential means such as photographs. It is argued that this visual tool will be helpful in evidence, showing how the welfare of an animal decreased, even with an improvement notice in place, justifying why the animal should be permanently removed from the owner and a need for a successful prosecution under s.9. As this tool can be done with the aid of a veterinarian, this could strengthen their own expert evidence and help to combat claims that the RSPCA have been removing animals from owners unnecessarily.

Further, there has been comments that veterinarians can be apprehensive to give evidence in court, due to fear of report writing and a lack of knowledge and skills to do so (van Bollenhoven et al. 2012). Studies have shown that an assessment of veterinary reports by experts differ significantly in the opinions of suffering and the actions of an owner (Baumgaertner et al. 2016). This tool may help to create consistency between veterinary reports and to prepare for presenting expert evidence in court, using the EWAG as an aid to their opinion of the animal's mistreatment before them.

\section{Potential Issues with the EWAG}

The EWAG and its use in animal welfare protection cases looks promising theoretically, but there are some issues which may be encountered when trying to use this tool in practice. Firstly, this tool is designed in experimental trials using specific software designed by CRACK IT solutions, in conjunction with Public Health England (NC3Rs). It is not envisaged that RSPCA Inspectors or other inspectors will have access to this tool via software, which may make the process timelier. Veterinarians may have access, which could help with the assessment, but this will then 
require the need for veterinarian support for every improvement notice, whether statutory or otherwise.

Secondly, it has been highlighted that this tool can be quite subjective, and some comment that it is somewhat arbitrary. Whilst the criticism of the subjectivity of the tool is appreciated, it is those who are experts who will be completing it, so their knowledge and expertise will mean this subjectivity is necessary. Williams, who uses this tool in veterinary hospitals, states that 'the focus achieved on the welfare of the animal, which can be rather lost with the emphasis on clinical treatment, can optimise steps taken to improve the welfare of the animal' (Williams 2018). He further highlights that it can help facilitate discussions between those that care for an animal and how to minimise the impact of their suffering (Williams 2018). In a similar setting, where many different bodies and people are involved in improving the welfare needs of an animal, this tool can help aid discussion between different bodies and focus their attention on the best option to minimise suffering.

Honess and Wolfensohn also appreciate the limitations of the tool and state, it is important to remember that welfare assessment alone is not sufficient. While we wish to evaluate an animal's quality of life, the animal's perception of its own welfare is not affected by the purpose for which it is maintained (experiential, breeding etc.) or the cause of its suffering' (2010, 211). This is true, particularly when considering that it is not only domestic animals which fall under the protection of AWA, but also farm animals and those used in entertainment. The welfare of an animal can be affected due to the reasons for which they are kept (Botreau et al. 2009) and other aspects need to be taken into account, beyond welfare. This is something which Botreau et al. highlighted with their assessment tool, stating that 'any method relying on the definition of a small number of categories will always carry threshold effects, and a farm or slaughterhouse manager may not have an interest in first improving the most problematic point detected on their farm/slaughter house' $(2009,369)$. Thus, this tool is appropriate and would work in cases such as farmed animals, but it may not be welcomed and is envisaged that it will be more beneficial to domestic pets at this time.

\section{Next Steps}

This paper has outlined, theoretically, how the EWAG is beneficial to welfare offence cases under the Animal Welfare Act 2006, both as a tool for improvement notices and as evidence, if needed in a subsequent prosecution. This tool will be developed further, by working with relevant stakeholders who are involved, and are qualified to assess, animal welfare. As Norwood and Lusk have identified, measuring animal welfare is difficult and that whilst "we possess indicators of animal well-being levels... we have no method of aggregating those indicators into a single well-being measurement that is agreed upon by all scientists' (Norwood and Lusk 2011, 96). These indicators include several factors, such as health, stress hormone levels and behaviour and preference indicators (2009, 
107). No one stakeholder carries expertise in all areas of animal welfare, and having knowledge of another expert's field may not be present in assessments (Hewson 2003). Thus, for the development of the EWAG for animal welfare cases under AWA, it is imperative to gain the opinions and work with the experience of veterinarians, animal behaviour specialists, the RSPCA, and others who may have an interest, such as DEFRA.

The next stage of this research is to work with various stakeholders across the country, providing them with multiple animal welfare case scenarios and ask them to plot how mild or severe the suffering of that particular animal is. By replicating this study with different experts, it is possible to explore how the EWAG would work in practice and what factors need to be considered when developing the welfare indicator key.

\section{Conclusion}

The RSPCA contribute greatly to the protection of animals, and ensuring that those who commit animal welfare offences are brought to justice. It is unfortunate that in recent times they have faced great criticism over their work, which led to a Parliamentary debate over their prosecution powers, and where their efforts should be focused. The RSPCA, whilst stating that they play a valuable role in enforcement of animal welfare law in England and Wales which has 'undoubtedly contributed significantly to the law's overall effectiveness' (Anderson 2012, 288), understood that they needed to strengthen their internal processes and governance of their prosecution function (RSPCA 2014). This paper has outlined the need for a tool such as the EWAG in animal welfare cases, and how it can be beneficial to those working in the field, particularly the RSPCA, as well as the owners of domesticated animals. Whilst there have been various animal welfare assessment grids implemented in the past, there are issues with how they are used and the consistency between different experts. Something that is visual, which has been shown to increase engagement and motivation, and used with owners, as a team member in improve their companion animal's welfare, is preferable, to a grid which is difficult to use and understand.

Further research and consultation is needed before this can potentially be implemented, but there is scope and interest from various experts to do this. It is imperative that different stakeholders are involved in the design of the EWAG, in order that it is used consistently and effectively across the jurisdiction. The next stage of the research is to do this, and begin to test the EWAG in animal welfare cases practically.

\section{Compliance with Ethical Standards}

Conflict of interest The author states that there is no conflict of interest.

Open Access This article is licensed under a Creative Commons Attribution 4.0 International License, which permits use, sharing, adaptation, distribution and reproduction in any medium or format, as long as you give appropriate credit to the original author(s) and the source, provide a link to the Creative 
Commons licence, and indicate if changes were made. The images or other third party material in this article are included in the article's Creative Commons licence, unless indicated otherwise in a credit line to the material. If material is not included in the article's Creative Commons licence and your intended use is not permitted by statutory regulation or exceeds the permitted use, you will need to obtain permission directly from the copyright holder. To view a copy of this licence, visit http://creativecommons.org/ licenses/by/4.0/.

\section{References}

Anderson, J.L. 2012. The origins and efficacy of private enforcement of animal cruelty law in Britain. Drake Journal of Agriculture 17: 263.

Baumgaertner, H., S. Mullan, and D.C.J. Main. 2016. Assessment of unnecessary suffering in animals by veterinary experts. Veterinary Record 179 (12): 307.

BBC. 2014. Ethics guide, animal welfare law in the UK. http://www.bbc.co.uk/ethics/animals/overview/ latest.shtml. Accessed 23 Mar 19.

Bilalis, N., G. Scroubelos, A. Antoniadis, and D.E. Koulouriotis. 2002. Visual factory: Basic principles and the 'Zoning' approach. International Journal of Productive Research 40 (15): 3575.

Botreau, Raphaelle, Isabelle Veissier, and Patrice Perny. 2009. Overall assessment of animal welfare: strategy adopted in welfare quality. Animal Welfare 18 (4): 363.

British Veterinary Association and British Small Animal Veterinary Association. 2016. Consultation Response: EFRA Committee Inquiry into Domestic Animal Welfare.

Countryside Alliance. 2017. The RSPCA, bad governance and a shaky future for animal welfare. https ://www.countryside-alliance.org/news/rspca-bad-governance-shaky-future-animal-welfare Accessed 26 April 2019.

Department Environment, Food and Rural Affairs. Guidance for Inspectors on the Issue of Improvement Notices Under Section 10(1) of the Animal Welfare Act 2006, https://webarchive.nationalarchive s.gov.uk/20130402190803/http://archive.defra.gov.uk/foodfarm/farmanimal/welfare/act/documents/ int-guidance.pdf. Accessed 23 Mar 19.

Eaidgah, Y., A. Arab Makie, K. Kurczewski, and A. Abdekhodaee. 2016. Visual management, performance management and continuous improvement: A lean manufacturing approach. International Journal of Lean Six 7 (2): 187.

Fordyce, P.S. 2017. Welfare, law and ethics in the veterinary intensive care unit: (A discussion of the different types of suffering that patients may endure in the veterinary intensive care unit, the legal limits to that suffering, and the ethics underpinning at what point that suffering becomes 'un-necessary'). Veterinary Anaesthesia and Analgesia 44 (2): 203.

Garcia-Retamero, R., and E.T. Cokely. 2013. Communicating health risks with visual aids. Current Directions in Psychological Science 22 (5): 392.

Hawkins, P. 2002. Recognizing and assessing pain, suffering and distress in laboratory animals: A survey of current practice in the UK with recommendations. Laboratory Animals 36 (4): 378.

Hawkins, P., D.B. Morton, O. Burman, N. Dennison, P. Honess, M. Jennings, S. Lane, V. Middleton, J.V. Roughan, S. Wells, and K. Westwood. 2011. A guide to defining and implementing protocols for the welfare assessment of laboratory animals: Eleventh report of the BVAAWF/FRAME/RSPCA/ UFAW Joint Working Group on Refinement. Laboratory Animals 24: 1.

Heuston, C.E.M., A. Greter, N. Diether, M. Moggy, M. Jelinski, C. Windeyer, D. Moya, E.A. Pajor, E.D. Janzen, and K.S. Schwartzkopf-Genswein. 2017. Benchmarking indicators of compromised and unfit conditions in cattle arriving a auctions and abattoirs in Alberta. Journal of Animal Science 95 (supplement 4): 7.

Hewson, C.J. 2003. Can we assess welfare? The Canadian Veterinary Journal 44 (9): 749.

Honess, P., and S. Wolfensohn. 2010. The extended welfare assessment grid: A matrix for the assessment of welfare and cumulative suffering in experiential animals. Alternatives to Laboratory Animals 38: 205.

Hope, C. 2016. RSPCA moves to stop animals being seized without vet's evidence after years of criticism. The Telegraph. https://www.telegraph.co.uk/finance/newsbysector/epic/htg/12174907/RSPCA 
-moves-to-stop-inspectors-seizing-animals-without-vets-evidence-after-years-of-criticism.html Accessed 26 April 2019.

Jaca, C., E. Viles, D. Jurburg, and M. Tanco. 2014. Do companies with greater deployment of participation systems use visual management more extensively? An exploratory study. International Journal of Productive Research 52 (6): 1755.

Justice, W.S.M., M.F. O’Brien, O. Szyszka, J. Shotton, J.E.M. Gilmour, P. Riordan, and S. Wolfensohn. 2017. Adaption of the animal welfare assessment grid (AWAG) for monitoring animal welfare in zoological collections. Veterinary Record 181 (6): 143.

Kirchner, M.K., H. Schulze Westerath, U. Knierim, E. Tessitore, G. Cozzi, and C. Winckler. 2014. Onfarm animal welfare assessment in beef bulls: consistency over time of single measures and aggregated Welfare Quality ${ }^{\circledR}$ scores. Animal 8 (3): 461.

McCulloch, S.P., and M.J. Reiss. 2017. The Development of an Animal Welfare Impact Assessment (AWIA) tool and its application to bovine tuberculosis and badger control in England. Journal of Agriculture and Environmental Ethics 30: 485.

NC3Rs, Development and evaluation of the Animal Welfare Assessment Grid (AWAG) https://www.nc3rs .org.uk/development-and-evaluation-animal-welfare-assessment-grid-awag Accessed 15 May 2019.

Norwood, F.B., and J.L. Lusk. 2011. Compassion, by the pound: The economics of farm animal welfare. Oxford: Oxford Scholarship Online.

RSPCA. 2018. Facts and Figures. https://www.rspca.org.uk/whatwedo/latest/facts Accessed 26 Feb 2020.

RSPCA (a). 2018. Prosecutions Annual Report 2018. https://www.rspca.org.uk/documents/14949 39/7712578/ProsecutionReport2019.pdf/a2ae6cdc-efe2-f6bf-cac3-0fb53da37bf6?t=1556101041 009. Accessed 26 April 2019.

RSPCA. 2014. The RSPCA's response to the Wooler review of its prosecution activity. https://www.alaw. org.uk/wp-content/uploads/rspca-response-wooler-review.pdf Accessed 27 Feb 2020.

Snowdon, K. 2017. RSPCA reveals animal cruelty investigations rose by nearly 5\% in a year. Huffington Post. https://guce.huffingtonpost.co.uk/copyConsent?sessionId=3_cc-session_0ae072ed-17af-4b4b8db8-505ad5b674a9\&inline=false\&lang=en-gb. Accessed 26 April 2019.

Stull, C.L., B.A. Reed, and S.L. Berry. 2005. A comparison of three animal welfare assessment programs on california dairies. American Dairy Association 88 (4): 1595.

The National Archives. 2009. Questions and answers: Local authority training sessions. https://webar chive.nationalarchives.gov.uk/20090731221305/http://www.defra.gov.uk//animalh/welfare/act/las_ qanda.htm\#2. Accessed 23 Mar 2019.

van Bollenhoven, E., Sonntag, Q., and Zeiler, G. 2012. The role of the veterinarian in the prosecution of cases of animal abuse: Writing expert witness reports. South African Veterinary Council newsletter. https://www.savc.org.za/pdf_docs/Report_Writing_\%20Article_SAVC_2012.pdf. Accessed 25 Feb 2020.

Williams, D.L. 2018. Using the extended welfare assessment grid to evaluate welfare in clinical settings. UFAW conference, Newcastle upon Tyne, June 2018.

Wolfensohn, S., S. Sharpe, I. Hall, S. Lawrence, S. Kitchen, and M. Dennis. 2015. Refinement of welfare through development of a quantitative system for assessment of lifetime experience. Animal Welfare 24 (2): 139.

Wooler, S. 2014. The independent review of the prosecution activity of the Royal Society for the Prevention of Cruelty to Animal. https://www.rspca.org.uk/webContent/staticImages/Downloads/Woole rReviewFinalSept2014.pdf. Accessed 30 April 2020.

Publisher's Note Springer Nature remains neutral with regard to jurisdictional claims in published maps and institutional affiliations.

\section{Affiliations}

\section{Rachel Ann Dunn ${ }^{1}$}

1 School of Law, Northumbria University, Newcastle upon Tyne NE1 8ST, UK 